\title{
UM PASSO PARA FORA DA SALA DE AULA: NOVOS LETRAMENTOS, MÍDIAS E TECNOLOGIAS ${ }^{1}$
}

\author{
Taking A Step Out of the Classroom: New Literacies, Media and Technologies
}

Luiz Henrique MAGNANI - USP

\section{RESUMO:}

Caso tencionem abarcar práticas de linguagem relacionadas às novas mídias e tecnologias, estudos sobre letramentos devem estar dispostos a abordar uma realidade complexa que demanda processos particulares de construção de sentido e novas formas de troca não redutíveis a relações escolares mais tradicionais. Isso demanda uma reflexão que inclua, ao menos, dois pontos: a ênfase em outros contextos que não o da sala de aula e a percepção de que toda prática letrada sempre será sinestésica e assim deverá ser abordada. Busca-se, nesse trabalho, compreender como práticas ligadas a esses novos contextos têm sido abordadas nos estudos do letramento. Diante disso, defende-se que tais estudos estejam dentro de uma abordagem política e ética frente à linguagem em uso nas mais diversas esferas sociais e relacionadas a um contexto de distribuição desigual de poder, do qual o ambiente escolar é mais uma instância. Argumenta-se a favor de mais pesquisas que tenham como foco práticas em espaços extraescolares - envolvendo novas mídias e tecnologias ou não - e que partam do local em que elas efetivamente ocorrem. Isso, mantendo-se o foco em uma busca por espaços que possam fomentar uma reflexão social crítica.

PALAVRAS-CHAVE: Novos Letramentos; Novas Tecnologias; Novas Mídias; Construção de Sentido; Práticas Letradas; Aprendizado Distribuído

\begin{abstract}
:
Intending to deal with practices of language related to new media and technologies, new literacy studies must be willing to discuss a complex reality that demands specific meaning-making processes and new ways of sharing not reducible to the traditional school. This calls for a way of thinking that includes at least two points: an emphasis on other contexts than the classroom dynamics and an idea that every language practice will be synesthetic. This paper tries to understand how practices related to these new contexts have been researched in literacy studies. It also argues that such studies should be part of a broader political and ethical approach to uses of language in various social spheres. These uses needs to be related to a wide context of unequal distribution of power: the school is one more instance instance of language use in one of such spheres. This paper recommends more researches focused on extracurricular practices - involving new media and technologies or not based on localities where such practices actually occur. All of that while keeping the focus on spaces that can foster a critical and social way of thinking.
\end{abstract}

KEYWORDS: New Literacies; New Technologies; New Media; Meaning-making; Literacy Practices; Distributed Learning

\section{NOVOS LETRAMENTOS, MULTILETRAMENTOS E CRITICIDADE: BREVE HISTÓRICO}

1 Este artigo é resultado parcial de pesquisa realizada com apoio financeiro da FAPESP, processo $\mathrm{n}^{\circ}$ 2010/07050-5 
O uso do termo "novos letramentos" como tradução a uma corrente de pensamento de alguns autores anglófonos pode causar estranhamento no português do Brasil, já que o próprio termo "letramento" data de pouco tempo. Mais que isso, é um conceito também pouco divulgado fora de um ambiente acadêmico especializado. Nas esferas do senso comum, alfabetização - como o processo de se tornar alguém detentor de uma não muito clara habilidade genérica de se ler ou escrever - ainda está no centro da discussão sobre aprendizado e práticas concretas de uso da língua.

O termo "alfabetismo", concorrente de "letramento", não chegou a ter uma vida acadêmica muito longa ou notória. Revelador, quanto a isso, é o trabalho de Soares (2003). A autora reaviva uma publicação de 1995 em que afirma que o termo 'alfabetismo' causava "estranheza aos falantes do português, enquanto seu contrário, seja termo de utilização corrente" (SOARES, 2003, p. 28). Em seguida, em uma nota destacada, a autora comenta que após a época da publicação original, a palavra letramento (como termo correspondente) foi se revelando uma preferência na bibliografia da área, tornando-se dicionarizada apenas em 2001.

Essa não é, no entanto, a mesma relação que a língua inglesa possui com o seu termo correspondente - literacy. Além de possuir uma trajetória mais extensa e mais disputada, vale explicitar que o conceito de "novos letramentos", apesar de não ser uma tradução direta de New Literacy Studies (a partir de agora, NLS), evoca tal corrente como parte constitutiva de sua história, como também faz com outras abordagens historicamente situadads, como é também o caso dos Multiliteracies (traduzido como Multiletramentos) e Critical Literacy (traduzido como Letramento Crítico). Assim, o diálogo que está se estabelecendo possui uma genealogia muito mais extensa do que uma década. Diante desse descompasso entre a trajetória do termo em inglês e de seu correspondente vernáculo, soa prudente trazer alguns pontos centrais dessa trajetória do termo literacy $^{2}$ na bibliografia especializada, principalmente no que diz respeito à mudança conceitual que fez surgir perspectivas teóricas recentes como as dos Multiletramentos ou dos NLS.

Para Street (2005), mais do que uma simples alcunha, a abordagem dos NLS “representa uma mudança na perspectiva no estudo e na aquisição do letramento, de modelo cognitivo dominante, com sua ênfase na leitura, para uma compreensão mais ampla das práticas de letramento em seus contextos sociais e culturais”3 (p. 417). A visão tradicional e bastante arraigada no debate público sobre letramento que se combate é principalmente a que entende letramento de um ponto de vista

2 De agora em diante, vou utilizar o termo "letramento" como tradução à literacy, assumindo que a diferença de trajetória de ambos já foi explicitada.

3 As traduções de citações e referências cujo texto original está em inglês são de minha autoria. 
meramente individual e cognitivo, uma habilidade ou um conjunto de habilidades abstratas e sem necessária relação com a realidade social. Ou como define Barton:

como uma variável psicológica que pode ser medida e acessada. Habilidades/competências são tratadas como coisas que as pessoas têm ou possuem; algumas habilidades são transferíveis, outras não. Aprender a ler se torna um problema técnico e o leitor de sucesso é um leitor hábil. Sendo uma definição de letramento baseada na escola, essa visão é bastante poderosa e é aquela que repercute no resto da sociedade. É importante perceber que essa ideia de habilidades é uma maneira particular de pensar o letramento (...) (BARTON, 1994, p. 12).

Para os NLS, essa maneira de se pensar o conceito é simplista e inadequada para tratar a complexidade com que um sujeito concreto lida com a linguagem em seu cotidiano também concreto. Rejeita-se também uma conclusão que costuma vir como consequência dessa visão: a de que o domínio de leitura pode ser segmentado e testado. E de que o processo para se fazer isso envolve a "quebra" dessa habilidade, indo de etapas simples a complexas cujas partes podem ser avaliadas independentemente.

Como alternativa, teóricos em linha com a abordagem dos NLS tendem a propor uma visão que relacione letramento, linguagem em uso e práticas sociais de modo contingente dentro de comunidades concretas. "Situar" é a chave para essa nova visão. Scribner e Cole (1981) e Heath (1983) são exemplos de estudos consagrados que fortaleceram tal abordagem. Em ambos os casos, mostrou-se que as práticas de linguagem dos sujeitos em análise possuem estrita relação com o contexto ao qual ele é exposto. Escrita e linguagem não são necessariamente transferíveis de uma esfera a outra e o sucesso na interação em um entorno sociocultural não garante uma habilidade geral em se ler ou escrever. Mais que isso, Heath (1983) mostra especificamente que - justamente por conta disso - sujeitos de comunidades cujas práticas letradas são divergentes das exigidas em sala de aula podem vir a ter mais dificuldade em prosseguir na educação formal.

Tais conflitos mostram que o mesmo termo "letramento" pode ter genealogias e pressupostos diferentes que o sustentam em cada caso e que estudos sobre o tema podem partir para os mais diversos rumos. Auerbach (2001), ao discutir multiletramentos centrada na relação das famílias do sujeito com práticas cotidianas, aponta o que considera os principais rumos e abordagens dos trabalhos subsequentes ao iniciado pela geração de Heath (1983). Dividindo tais perspectivas em três tendências - visão baseada em habilidades, visão de práticas sociais e visão transformativa/crítica - a autora sai em defesa da última, uma forma de letramento que parta dos problemas sociais no contexto dos sujeitos e sirva como ferramenta para a compreensão crítica e para a mudança social. Além disso, preconiza a necessidade de se ter clareza quanto aos pressupostos ideológicos que sustentam as perspectivas existentes (inclusive nossas) sobre o que é letramento a fim de se compreender melhor de que forma está se agindo politicamente no mundo. 


\section{DOSSIÊ ESPECIAL \\ JORDÃO (org.) Letramentos e Multiletramentos no Ensino de Línguas e Literaturas. \\ Revista X, vol.1, 2011}

Essa terceira visão é a que tende a ser partilhada por teóricos que pesquisam/agem a partir dos NLS e dos Multiletramentos. Grosso modo, tais estudiosos não só se distanciam de uma visão acadêmica mais tradicional por julgarem central um estudo situado, como tais perspectivas também são bem delineadas ética e politicamente ao terem como meta o fomento de um espaço que dê voz a sujeitos de comunidades não favorecidas pela estrutura social. De um ponto de vista linguístico e semiótico, o grande mérito dessas novas propostas consiste em chamar a atenção para o fato de que a relação com a língua e o aprendizado de linguagens não é algo abstrato, mas diversificado e dependente do contexto cultural. Assim, se explicações universais ou universalizantes tendem a silenciar as vozes dissonantes valorizando algumas localidades e práticas em detrimento de outras, o foco na complexidade local dá a oportunidade de refletir sobre as conflituosas diferenças culturais e sua relação com os usos concretos da língua.

Além disso, a construção de sentido - seja na leitura de um texto impresso ou na leitura do mundo - é vista como um processo ativo, no qual o interlocutor tem papel fundamental. É essa a noção que Cervetti, Pardales e Damico (2001) possuem a respeito do que seria um "letramento crítico", dentro do qual a construção de sentido frente a textos seria:

\footnotetext{
um processo de construção, não de exegese; atribui-se sentido a um texto em vez de extrair dele tal sentido. Mais importante, o sentido do texto é compreendido no contexto de relações sociais, históricas e de poder, e não somente como o produto ou a intenção de um autor. Ademais, ler é um ato de vir a conhecer o mundo (bem como a palavra) e um meio para a transformação social (CERVETTI, PARDALES e DAMICO, 2001, p. 6).
}

Esse processo ativo também é bem marcado entre teóricos dos Multiletramentos, quando entendem que todo momento de significação envolve transformação das fontes disponíveis de sentido. Em particular, Kalantzis e Cope (2001, p. 12) apontam que "transformamos ou recriamos sentido todo o tempo" e que, sendo assim, "somos verdadeiramente designers dos nossos futuros sociais". Perspectiva que desloca a relação que o sujeito possui com a linguagem, a construção de sentidos e o aprendizado. Agora, o sujeito não assimila passivamente conteúdos, opiniões e conhecimentos, mas os articula, em um trabalho ativo, em relação a sua trajetória, seus conhecimentos prévios e seus interesses. Desse modo, é um sujeito que participa da constante criação da sociedade em cada ato de construção de sentido e, sendo assim, também está hábil para transformá-la.

A partir desse breve histórico, é possível destacar ao menos dois grandes méritos das perspectivas apresentadas sobre letramento. Em primeiro lugar, o foco na reflexão analítica da língua em uso, percebida em um contexto concreto compreendido em dois níveis: o da situação imediata, 
com suas particularidades locais; mas também o entorno social e político mais amplo no qual essas relações estão imersas. Em segundo lugar, a sensibilidade que a tendência em foco possui em relação aos problemas e conflitos a que esses usos da linguagem estão relacionados, bem como sua vocação para a crítica e transformação social, levando em conta uma estrutura não determinística de poder, em que o sujeito ainda que condicionado, age socialmente.

Por entender a construção de sentido dentro de relações culturais mais amplas, um olhar como esse pode ser o mais recomendado para se pensar sobre linguagens e letramentos dentro de uma demanda bastante atual - o das novas mídias e tecnologias. De um ponto de vista social, a grande vantagem dessa perspectiva é a sua preocupação com a criticidade, já que se assume não existirem interpretações universais que se dão no abstrato. Ao contrário, elas inevitavelmente fazem parte de lutas e conflitos sociais mais amplos. Do ponto de vista educacional, a sensibilidade com o contexto concreto de uso e o pressuposto de um pesquisador nele inserido auxilia na compreensão das matizes e particularidades das práticas em análise, algo que tende ficar de lado em abordagens mais generalizantes.

Alguns teóricos inseridos nessa perspectiva de letramento já têm tentado incluir, de um modo ou de outro, práticas relacionadas às novas mídias e tecnologias nas reflexões sobre o tema. A seção a seguir é destinada a apresentar e analisar alguns desses trabalhos.

\section{NOVOS LETRAMENTOS, MÍDIAS E TECNOLOGIAS}

Para Bolter (2000), vivemos na 'era tardia do impresso', momento em que elementos computacionais/digitais estão, para diversas finalidades, substituindo práticas anteriormente consagradas. O autor também destaca uma condição curiosa e aparentemente paradoxal do texto impresso: mesmo que ele permaneça indispensável nessa era tardia, ele já não o parece mais. Ainda enfatiza que muitos acadêmicos, de perspectivas diversas, tendem a concordar que o período em que vivemos é mais visual que linguístico.

São condições que certamente provocam os estudos do letramento. "Todo letramento é letramento multimidiático", preconiza Lemke (2010, p. 456), alegando que não se constrói significado com a língua de forma isolada e que todo signo linguístico carrega significado nãolinguístico. Um posicionamento como esse exige, por consequência, uma noção de letramento centrada na construção de sentidos, não fechando o escopo na leitura e na escrita ou, mais especificamente, no texto verbal impresso. É uma visão propícia, portanto, para tentar dar conta da

4 No original, "Late age of print". 
recorrente exploração de formas de linguagem diversas presentes e articuladas nas práticas imersas em contextos de novas mídias e tecnologias.

Tais práticas também costumam convergir com o ideal de postura ativa especialmente esperada por estudiosos dos Multiletramentos. O foco na agência, aliás, explica o uso do termo redesign para designar o processo pelo qual o sujeito reconstrói e transforma os sentidos a partir dos recursos semióticos disponíveis (KALANTZIS e COPE, 2001). De modo análogo, Lankshear e Knobel (2006) entendem os novos letramentos dentro de uma expansão conceitual do termo remix: prática de manipular artefatos culturais e recombiná-los, gerando novas misturas e novos sentidos. Dentro desse contexto, os autores concebem o remix como uma forma contemporânea de escrita, considerando que "escrever" não é algo só feito com o texto verbal impresso, mas pode ser feito de uma forma multimodal - algo cada vez mais evidenciado pelas facilidades trazidas pelas novas tecnologias.

Em um posicionamento aparentemente análogo ao de muitos estudiosos pós-estruturalistas, Lankshear e Knobel (2006) defendem que essa prática de recombinar elementos existentes na criação de novos seria uma condição geral das culturas. Sem aquela, essas não existiriam. O modo como isso é feito dentro da disponibilidade das novas mídias é que é qualitativamente diferente. Como lembra Manovich (2003), o acúmulo de registros de mídia analógica que temos em mãos atualmente, somado à viabilidade tecnológica que a digitalização traz para transformar concretamente tais materiais em outros, cria algo qualitativamente novo. Com isso, artefatos e registros dessa espécie de grande arquivo podem se tornar partes de novas produções culturais e artísticas.

Essa tendência é que Lankshear e Knobel (2006) parecem assinalar quando falam em um remix digital possibilitado por computadores e que nos permite ir além de editar e manipular músicas. Com efeito, esse novo remix envolve composição com imagens, textos sons e animação. Algo que é feito em uma escala massiva e que se mostra bastante significativo, atualmente, enquanto prática de construir sentido e expressar ideias. Partindo disso, os autores expõem alguns exemplos dentre os quais, os memes de Internet ${ }^{5}$ - que ilustram processos razoavelmente prototípicos de remix digital. Em relação aos memes apresentados, pontuam que o sucesso dessa prática se deve, em grande parte, a esse trabalho ativo de remixagem. A longevidade do meme, para os autores, tem relação com a sua capacidade em ser parcialmente modificado (em relação aos recursos expressivos

5 Na concepção de Lankshear e Knobel (2006, p. 215), 'meme' é um termo popular entre "insiders" da Internet para descrever "a rápida percepção e disseminação de uma ideia particular" apresentada em alguma forma de mídia e linguagem culturamente reconhecida e aceita. Para os autores, é uma definição que está centrada na "longevidade" da ideia. Para compreender de modo mais prático o que são e de que modo circulam tais memes de Internet, sugere-se acessar a seguinte página: http://knowyourmeme.com/ , uma base de dados dedicada à pesquisar e catalogar a história e o surgimento dos mais diversos memes. 
utilizados) e repassado, mantendo sua ideia central contagiosa relativamente intacta. No âmbito mais geral, tendem a reiterar a ideia de as práticas analisadas estarem ligadas a um fazer coletivo e a usos criativos e ativo das formas de linguagem disponíveis.

Os memes de Internet são exemplos bastante ilustrativos de como o logocentrismo ou o foco em modalidades como instâncias em separado não dão conta de compreender novas práticas. Grande parte dessas produções apresenta-se como um conjunto indissociável de modalidades e recursos empregados de modo não aleatório sendo que, comumente, envolvem pelo menos um elemento verbal e um visual. Além disso, também são exemplos interessante de como o sujeito pode colaborar ativa e publicamente na construção de sentido de algo coletivo. O convite para testar e "remixar" está sempre em aberto, e o resultado da remixagem, quando publicado, é filtrado e julgado pela própria comunidade na qual o meme deve(ria) fazer sentido.

O olhar que os autores dizem sustentar em relação aos novos letramentos traria um interesse na prática social como um todo, dentro da qual o aprendizado, a troca de conhecimento e expertise é uma parte. Porém, é curioso notar que ambas as características destacadas nos memes - postura ativa e integração de várias modalidades - parecem ser vistas a partir de um olhar comparativo, de uma localidade bastante específica que pressupõe o prestígio do logocentrismo e de formas menos distribuídas de saber.

Não é um acaso, aliás, que essa análise comparativa chame a atenção justamente para elementos que têm sido problematizados dentro do contexto escolar. Afinal, o local de que falam Lankshear e Knobel (2006) ainda parece ser a sala de aula, ainda que colocada em cheque por outras práticas de aprendizado. Não é à toa que vinculam expressamente a reflexão sobre novas práticas de letramentos com um convite para se pensar sobre o processo educativo do letramento e sobre o aprendizado na escola. Destacam também ser importante entender o tempo utilizado em espaços de afinidade da Internet como uma dimensão da aprendizagem, para depois ressaltar positivamente algumas características como a participação, colaboração, distribuição e dispersão de expertise elementos cuja ausência tende a ser sentida em geral nas críticas sobre contextos formais de ensino.

Muitas propostas que decorrem dessa análise também permanecem nessa linha. Os autores sugerem, por exemplo, maneiras potencialmente frutíferas de certos memes por eles trazidos servirem como exemplos ou estudos de caso a serem analisados por alunos e professores. A ideia, válida, parece ser qualitativamente semelhante a outras propostas, anteriores, de se tomar outras práticas ou gêneros (sejam anúncios publicitários ou notícias de jornal) como ponto de partida.

Isso não parece ser um caso isolado. Algo semelhante se observa no estudo que Gee (2003) desenvolve em relação a videogames e ensino. $\mathrm{O}$ autor dedica um livro inteiro a refletir sobre tal 


\section{DOSSIÊ ESPECIAL \\ JORDÃO (org.) Letramentos e Multiletramentos no Ensino de Línguas e Literaturas. \\ Revista X, vol.1, 2011}

mídia como um próspero modelo de aprendizado e letramento. Dentro disso, pressupõe contextos em que o aprendizado escolar não é tão atrativo e destaca um conjunto de princípios de aprendizado observados em videogames de sucesso, os quais, para Gee, conseguem ensinar aquilo a que se propõem. Para se ficar em outros poucos exemplos de uma lista maior de estudos com abordagens convergentes, vale também mencionar trabalhos como o de Rowsell e Burke (2009) ou de Nahachewsky e Begoray (2010), ambos centrados no aprender na sala de aula e propondo reflexões sobre aspectos relacionados às novas tecnologias nesse processo.

Nota-se, portanto, a existência de uma corrente de estudos do letramento que abordam questões referentes a novas mídias e tecnologias como inspirações ou exemplos a serem seguidos ainda que utopicamente - para se repensar a sala de aula. É deste local que tais pesquisas normalmente costumam falar e as novas tecnologias, mídias e as práticas a elas ligadas - memes, blogs, fóruns cibernéticos, videogames - tendem a ser trazidas como um elemento de alteridade ou contraste para o que se intui ou se supõe estar faltando no contexto formal de ensino.

A motivação e a sustentação dessa tendência podem, em partes, ser explicadas a partir de algumas ponderações de Lemke (2010) sobre aprendizado e novas tecnologias. A partir de uma perspectiva que assume a educação mais amplamente como "iniciação em comunidades e especialmente em práticas de letramento genéricas e especializadas", o autor entende que "novas tecnologias da informação, novas práticas de comunicação e novas redes sociais possibilitam novos paradigmas para a educação e a aprendizagem, e colocam em debate os pressupostos sobre os quais os paradigmas mais antigos se apoiam" (LEMKE, 2010, p. 461). O autor aponta para dois paradigmas correntes em disputa. De um lado, haveria o paradigma da aprendizagem curricular, presente em universidades e escolas e próprio do capitalismo industrial e da produção em massa. De outro, o da aprendizagem interativa, comum às bibliotecas e centros de pesquisa, em que as pessoas, com base em dúvidas e empecilhos gerados por participações concretas em atividades específicas, determinam o que precisam saber, na ordem e no ritmo que lhe cabem. Seria também aquele potencializado pelas possibilidades que oferecem as novas mídias e tecnologias. Para Lemke (2010), além de este segundo ser o modo "como pessoas com poder e recursos escolhem aprender" (p.469), seria também o paradigma próprio de um novo capitalismo, favorecendo grupos de trabalho com sujeitos flexíveis; observação em linha com o que defendem e discutem outros teóricos do letramento (GEE, 2001; KALANTZIS e COPE, 2001). Além disso, Lemke pondera a existência de um conflito amplo e não reconhecido entre ambos os paradigmas de aprendizagem, conflito que pode ser base para muitos impasses atuais presentes no ambiente escolar. 


\section{DOSSIÊ ESPECIAL \\ JORDÃO (org.) Letramentos e Multiletramentos no Ensino de Línguas e Literaturas. \\ Revista X, vol.1, 2011}

Isso traz um novo contexto para as relações existentes entre práticas letradas escolares e extraescolares. Em muitos casos anteriores, o que ocorria e era investigado fora da sala de aula era trazido para a pauta das discussões de letramento e ensino para se compreender o contexto do aluno e suas possíveis relações e expectativas com o ensino formal. O trabalho de Heath (1983) foi significativo nesse sentido. A partir da compreensão das práticas letradas extraescolares presentes no contexto de duas comunidades de classes trabalhadoras estadunidenses, a autora desmistificou a crença de que crianças/alunos vindos desse grupo tinham dificuldades com leitura e escrita no geral. A maior dificuldade, nesses casos, estava nos conflitos e diferenças entre as demandas da escola, e as práticas familiares e cotidianas de membros dessas comunidades - periféricas e socialmente invisibilizadas.

Nesse caso, as formas extraescolares de letramento presentes no cotidiano das comunidades observadas e não contempladas em sala de aula tendiam a ser de menor prestígio em relação às previstas e estimuladas pelo professor. O conjunto de práticas extraescolares presentes em grupos de maior voz e prestígio, por sua vez, normalmente coincidia com o que era valorizado em sala de aula. Mas a sala de aula também é um espaço dinâmico: não só as abordagens mudam, como também mudam os professores e, principalmente, os estudantes que a frequentam e o contexto extraescolar que envolve a todos. Gerações diferentes, com trajetórias sociais diferentes e contextos sociais que mudam não só de local para local como, no passar do tempo, tendem a trazer uma contínua renovação no irremediavelmente heterogêneo perfil dos estudantes.

Aparentemente, essa mudança de prestígios faz emergir questionamentos a respeito de valores e noções anteriormente consagradas de aprendizado e currículo, linguagem e letramento, escola e ambiente extraescolar. Quando o espaço privilegiado da escola passa a ter uma concorrência mais efetiva de práticas extraescolares, uma perspectiva logocêntrica da linguagem passa também a dar lugar ao reconhecimento de uma maneira de construir sentidos que integra com naturalidade as mais diversas modalidades e do aprendizado como algo significativo e contextualizado ao sujeito se mostra mais efetivo. Além disso, o próprio sujeito se mostra agente participativo na construção de sentido.

Em suma, percebe-se que grande parte da busca e do mérito dos autores voltados às novas mídias e tecnologias aqui apresentados consiste em tomar como base práticas letradas comuns aos meios digitais para se questionar e repensar os conceitos e as dinâmicas comuns a uma sala de aula tradicionalmente conhecida e aparentemente em cheque. Também se destaca positivamente a compreensão de que a escola não centraliza todas as formas de saber e conhecimento que circulam dentro da sociedade. 


\section{DOSSIÊ ESPECIAL \\ JORDÃO (org.) Letramentos e Multiletramentos no Ensino de Línguas e Literaturas. \\ Revista X, vol.1, 2011}

Ainda assim, essa abordagem deixa em aberto algumas outras questões pertinentes, que também precisam ser compreendidas e respondidas. Deve-se lembrar que o contexto extraescolar não é passível de uma incorporação plena e inequívoca por parte de ambientes formais de ensino. Mais especificamente: de um lado, a escola não totaliza as formas de aprendizado, já que este é sempre distribuído; de outro, toda tentativa de deslocar algum elemento extraescolar a um contexto de sala de aula pressupõe recortes, reduções e traduções. Na passagem de um contexto a outro, o objeto se transforma, o enunciado já e outro, as razões e as motivações de cada agente também mudam, regidas pela dinâmica da sala de aula, dos pressupostos pedagógicos e das relações sociais e de poder que previamente existem nesse segundo espaço. Sendo assim, centralizar os estudos do letramento apenas na sala de aula pode significar, por vezes, deixar em segundo plano muitas outras maneiras usuais de construir sentidos e formar sujeitos. E a análises que se pretendam contrastiva, mas que ainda tomam como base a sala de aula, podem acabar deixando passar elementos relevantes do contexto de uso dessas novas linguagens

Isso nos leva a refletir que, se tais análises contrastivas ou, de modo mais abrangente, estudos sobre letramentos relacionados à escola são e continuam sendo importantes, por outro lado, não são a única possibilidade de se investigar letramento, aprendizado e construção de sentido. Aliás, também não são suficientes para trazer parâmetros e reflexões sobre os contextos de uso da língua e de linguagens que estão além do espaço da sala de aula.

Na seção a seguir, alguns desses impasses e questionamentos serão objeto de uma reflexão mais detalhada.

\section{A “ESCOLA FORA DA ESCOLA" EM FOCO}

Gomes (2010) reflete sobre letramentos existentes em contextos de comunidades de prática e redes sociais inseridas em novas mídias e tecnologias. Nisso, enfatiza o fato de que eles possibilitam novas formas de aprender e se relacionar com o conhecimento, ressaltando como elementos constitutivos dessas novas possibilidades a relação mais flexível com hierarquias e com o controle. A fim de refletir sobre tais práticas, o autor também esboça uma comparação com uma realidade recorrente no contexto escolar:

enquanto a escola reluta em introduzir as tecnologias atuais na mediação pedagógica, discute quem fica com a chave dos laboratórios de informática e se preocupa com o tempo que os jovens (e as crianças também!) ficam 'no computador' as conexões vão se fazendo, as comunidades de aprendizagem formadas espontaneamente vão se tornando cada vez mais importantes na distribuição e construção de conhecimentos e saberes. [...] A utilização dos recursos da multimodalidade para as interações nas diversas redes sociais e a tendência à centralidade da imagem em relação ao texto verbal também se constituem em opções por modos de expressão não valorizados na maioria das escolas. (GOMES, 2010, p. 8) 
Diante disso, o autor procura pensar sobre o que está ocorrendo fora de sala de aula para compreender melhor esse descompasso. A partir de então, arrisca associar essa prática de "estar no computador" a uma espécie de resistência em relação à escola e seu modo tradicional de construção de conhecimentos. $\mathrm{O}$ autor afirma que diversos usos sociais da escrita, por exemplo, têm ocorrido espontaneamente no meio digital, fora do contexto de sala de aula e, muitas vezes, por jovens em idade escolar. Considera, também, que nas redes sociais de que participam, os usuários fazem uso de gêneros, linguagens e normas de escrita muitas vezes não aceitas ou não privilegiadas pela escola. Tendo por base essas e outras considerações, defende que "por trás da anarquia, da descentralização, há uma atitude contracultural, no sentido em que não enfrenta a instituição escolar, mas silenciosamente protesta contra ela. Há uma escola fora da escola”. (GOMES, 2010, 3-4).

A existência de uma "escola fora da escola", em termos mais gerais, é uma condição das sociedades, como o próprio autor faz questão de destacar. Para tanto, retoma autores cuja argumentação é a de que aprendizados se dão nas localidades nas quais as pessoas circulam e, desse modo, a cidade e a sociedade é que são, no fim, as educadoras dos sujeitos (LEMKE 2002; FRANCO, 2010 apud GOMES, 2010). Porém, mais estritamente, esses espaços extraescolares de aprendizado têm sido particularmente destacados atualmente em análises comparativas com o ensino no contexto escolar, conforme apontado na seção anterior.

Aliás, notou-se também que esse espaço extraescolar tem cumprido um grande papel para se pensar em possíveis transformações na dinâmica da sala de aula. De outro lado, a idéia trazida por Gomes (2010) de que há algo de protesto e resistência em algumas dessas práticas extraescolares permite concluir que a recíproca, nesses casos, nem sempre é verdadeira: os espaços aprendizado presentes e distribuídos em toda a sociedade não se reduzem e nem querem, necessariamente, reduzir-se ao que é tido como pertinente ao contexto formal de ensino. Assim,

\footnotetext{
enquanto a instituição escolar rejeita ou demora a entender os efeitos enquanto procura as causas, ou procura domesticar as redes, na microestrutura as mudanças vão acontecendo, se não dentro da escola, ao menos fora dela. A escola vai se reinventando fora da escola (GOMES, 2010, p. 18).
}

Esse, enfim, é um primeiro ponto a favor de pesquisas que também discutam letramentos a partir das localidades próprias dos espaços distribuídos em que cada aprendizado ocorre.

Um segundo ponto que merece ser ressaltado nessa discussão diz respeito a um certo consenso até aqui percebido de que muitas práticas ligadas às novas mídias e tecnologias estão bastante alinhadas com muito do que é prestigiado atualmente em relação a formas de aprender e agir no mundo. Sobre isso, vale ressaltar que habilidades e comportamentos que costumam ser destacados nesses casos - como autonomia, capacidade para interagir com grupos ou flexibilidade - podem ser 
facilmente associados a exigências de um quadro cultural e econômico mais amplo de um novo capitalismo (GEE, 2001; KALANTZIS e COPE, 2001).

É de se esperar, por consequência, que sejam características valorizadas em vários contextos sociais, especialmente no mercado de trabalho. Isso não garante, porém, que sejam elementos tidos como consensualmente bons do ponto de vista da formação do sujeito para as mais diversas perspectivas educacionais. Nem que, estritamente dentro do viés defendido pelos NLS, os aprendizados de prestigio que os novos meios trazem sejam inquestionáveis.

Um exemplo disso pode ser visto a partir da prática de se interagir com o jogo World of Warcraft (WoW) ${ }^{6}$, como a análise feita por Rettberg (2008) permite concluir. Para o autor, o grande motivo pelo qual o jogo alcançou fama e repercussão mundial foi o fato de ele oferecer um convincente e detalhado simulacro de como seria o processo de "se tornar um sucesso" em sociedades capitalistas. Tendo isso como base, o autor considera que o jogo apresenta um modelo razoavelmente realista de mercado financeiro e, dentro disso, oferece aos jogadores um treinamento nas noções básicas de oferta e demanda, mercados e arbitragem de câmbio. Isso tudo, a despeito da sua temática ser aparentemente tão distante de uma realidade atual, evocando tempos imaginários, épocas fantasiosas, povos não existentes.

O que é interessante de se considerar, nesse caso, é o fato de que o exemplo trazido por Rettberg contempla dois elementos que costumam ser destacados de práticas relacionadas ao segundo paradigma de aprendizado de que fala Lemke (2010): primeiro, interagir com o jogo, considerando os sujeitos que nele se engajam voluntariamente, é aparentemente um modo sedutor de se aprender e de se compartilhar conhecimento; segundo, muito do que o jogo ensina pode ser visto como desejável, por alguns, para se estar alinhado ao sistema econômico vigente.

No entanto, os pressupostos ideológicos da bibliografia sobre letramentos defendidos por Auaerbach (2001), por exemplo, certamente entrariam em conflito com muitos dos conhecimentos propriamente ditos cujo aprendizado, na visão do autor, é permitido e fomentado na interação com o WoW. Rettberg argumenta que, em um sentido mais amplo, o jogo tem treinado uma "geração de bons cidadão corporativos" não só para atividades como pagar impostos e consumir bastante, mas também para encarnar o sujeito do modelo competitivo no mercado transformando-os em melhores empregados ou até líderes que, entre outros, "escalam a ladeira corporativa", "atingem metas de

6 WoW, produzido pela Blizzard, é um dos mais populares videogames on-line da atualidade e conecta pessoas de diversas partes do mundo que interagem entre si. É situado no mundo fantástico de Azeroth, um planeta em que há uma constante tensão entre duas facções: a Horda e a Aliança. Sua temática é centrada na fantasia e em narrativas de guerras, envolvendo conflitos entre povos e monstros diversos. O jogador participa de Wow por meio de uma personagem que ele mesmo cria, a qual, dependendo de suas características, pertencerá a uma das duas facções. Mais informações podem ser obtidas no site oficial do jogo: http://www.batlle.net/wow 


\section{DOSSIÊ ESPECIAL \\ JORDÃO (org.) Letramentos e Multiletramentos no Ensino de Línguas e Literaturas. \\ Revista X, vol.1, 2011}

venda", "trabalham duro por melhores posses" e "ganham respeito dos pares e dos consumidores" (RETTBERG, 2008, p. 20).

Outros estudos e análises sobre videogames e questões políticas e sociais mais amplas podem também ilustrar essa necessidade. Em Langer (2008), a autora nota que, entre outras coisas, o modo como esse mesmo jogo é construído pode incentivar um processo radical de alterização de uma das facções representadas dentro daquele universo, em uma tensão que tende a fortalecer dicotomias como familiar/estrangeiro, civilizado/selvagem, eu/outro, centro/periferia. Em Magnani (2008a; 2008b), ao se analisar aspectos do jogo $\operatorname{The~Sims~}^{7}$, fica claro que, apesar de tal título não especificar, ele apresenta e reitera uma noção de família muito particular, inspirada em uma classe média suburbana norte-americana em que, entre outras coisas, não existe aluguel, crianças são vistas como investimento e todos os sujeitos presentes sabem ler.

Certamente, não se deve considerar, de modo determinista, que os pressupostos ideológicos presentes em um videogame serão meramente transmitidos a um jogador que os acata passivamente. Isso, no entanto, não invalida o fato de que o letramento presente nessa "escola fora da escola" das práticas digitais não é meramente ligado com habilidades em abstrato. Diferentemente, também sustenta e reitera visões de mundo e posicionamentos ideológicos específicos. Grande parte das tecnologias e/ou dos dispositivos que possibilitam essas novas práticas são produzidos dentro de (e, muitas vezes, graças à) uma lógica de mercado corporativo. Nesses casos, é de esperar uma tendência na qual os posicionamentos em pauta se mostrem parte dessa lógica ou mesmo simpatizantes a ela.

Dentro disso, pondera-se haver a necessidade de se voltar a um dos itens centrais dos estudos do letramento: o questionamento de "o quê" e "para que" se aprende e se deve aprender. Nem toda perspectiva ideológica aceitaria apelo ou atratividade como critério que garantisse o sucesso ou a superioridade de uma prática educacional. Como exemplo, pode-se trazer a ressalva feita pelos próprios Lankshear e Knobel (2006) ao falarem sobre memes. Os autores têm o cuidado de lembrar que memes não são necessariamente benignos socialmente. E, mais que isso, participar de uma prática como essa não é um ato inocente ou sem consequências sociais.

Qualquer aprendizado, em sua forma e seu conteúdo, possui uma localidade e está vinculado a modos de conceber e construir a realidade. Assim, tende sempre a favorecer conhecimentos e

7 Lançado em 2000, o jogo em questão é a primeira versão de uma série de bastante sucesso. Os videogames dessa série são vendidos como "simuladores de pessoas" ou "do cotidiano", dentro dos quais o usuário tomaria o lugar de uma espécie de "deus", podendo controlar a vida de diversas famílias em situações do dia a dia: alimentar-se, relacionar-se com outras pessoas, procurar emprego, comprar móveis, dormir. Informações oficiais sobre a série podem ser encontradas no seguinte link: http://thesims.ea.com 
verdades específicos, bem como modos de agir e pensar no mundo. Os efeitos de cada prática de aprendizado, portanto, devem ser constantemente investigados e colocados em debate. Exige-se, diante disso, um cuidado de se pensar eticamente sobre possíveis efeito das novas práticas que têm surgido e se fortalecido com as novas mídias e tecnologias.

Sabe-se, porém, que a escola é um local de crítica e transformação social historicamente privilegiado pelos estudos do letramento. E, nela, tal trabalho é (ou deveria ser) fomentado pelo professor. Essa expectativa tem suas bases em visões específicas de um contexto escolar razoavelmente estabilizado - embora por muitos combatido - em épocas anteriores, quando formas de compartilhamento de informação e de conhecimento via meio digital ainda não tinham o peso e a frequência atual. Mas, conforme foi apresentado, a própria sala de aula tem sido repensada em muitos aspectos. Como se não bastasse, uma das bases a partir da qual essa reflexão surge são as próprias práticas extraescolares de sucesso ligadas ao uso de novas tecnologias. Como, então, não cair em um círculo vicioso em que a discussão sobre transformação social e a discussão sobre responsabilidade ética e ação social não saia pela tangente?

Como resposta e inspiração, trazem-se alguns exemplos e tentativas de se abordar o contexto extraescolar de modo alternativo, buscando promover um engajamento politizado em relação a novas práticas em meio digital cujo foco está na "escola fora da escola". Uma delas encontra-se presente no próprio texto de Lankhsear e Knobel (2006), ainda que perifericamente. Quando os autores associam memes e aprendizado ao sujeito agente nos contextos de uso concreto, apresentam uma possibilidade existente, viável e direta de ação social: o counter-meming ${ }^{8}$, que consistiria em criar memes que tenham como meta política "neutralizar ou derrotar ideias prejudiciais". Essa prática, claramente engajada socialmente, é exequível dentro do contexto original no qual os memes aparecem e foi utilizada com sucesso, conforme os autores mostram, para se criticar e inibir a banalização do uso do termo “nazismo” em redes sociais específicas. (LANKSHEAR e KNOBEL, 2006, p. 238)

Outro exemplo é a tentativa de se criar videogames que tenham como meta promover a criticidade, algo que tem ocorrido com certa frequência atualmente (MAGNANI, 2008b). De um ponto de vista estritamente técnico, deve-se ponderar que essa proposta requer um conjunto de conhecimentos específicos que não está acessível a todos. Porém, por outro lado, também mostra que o sujeito politicamente engajado pode ser outro além do professor e que há outros espaços relevantes para a ação social e para o convite à reflexão crítica para além da sala de aula.

8 Uma tradução aproximada seria "contramemização", um verbo que traria a ideia de rebater ou contra-atacar ideias propagadas em certos memes a partir da criação de outros memes que respondessem ou contestassem os primeiros. 


\section{DOSSIÊ ESPECIAL \\ JORDÃO (org.) Letramentos e Multiletramentos no Ensino de Línguas e Literaturas. \\ Revista X, vol.1, 2011}

Com base em tudo que foi discutido nessa seção, argumenta-se que esse espaço extraescolar é complexo e amplo e tanto o que pode ser aprendido nesses espaços como a forma pela qual se aprende não é passível de uma transferência direta para o contexto escolar. Aliás, por vezes, alguns desses aprendizados socialmente distribuídos podem representar formas de resistência à sala de aula. Dessa forma, esses "excedentes" precisam ser mais bem estudados e pesquisados dentro dos contextos em que ocorrem, a fim de se compreender melhor tais formas de aprendizado, problemas a elas relacionados e suas relações com um contexto político e social mais amplo. No caso das novas mídias e tecnologias, vale lembrar que estamos falando, inclusive, de objetos/dispositivos que possuem uma realidade particular: um conjunto de regras, limites e possibilidades técnicas de um lado e protocolos e práticas associadas ao uso concreto local desses objetos, de outro lado. É assim, por exemplo, que algoritmos argumentam e criam realidades em videogames (MAGNANI, 2008a; 2008b) ou que produtores de jogos se assemelham a legisladores, criando não só um mundo, mas as regras que devem ser seguidas neles (FRASCA, 2001).

Compreender como o sentido é construído, nesses casos, deve envolver estudos que abarquem esse tipo de especificidade. Os poucos exemplos trazidos coincidem com o pouco que se tem estudado, dentro de uma perspectiva da linguagem em uso, desse contexto extraescolar e suas possibilidades como arena de lutas sociais e formação cultural. Mas são o suficiente para se colocar o foco nessa relação entre novos letramentos e formas de aprender e de agir social e politicamente.

\section{CONSIDERAÇÕES FINAIS}

Do ponto de vista acadêmico mais amplo, pesquisas sobre letramentos e linguagem em uso em contextos fora da escola são e serão de grande valia e não devem nem precisam estar amarrados a uma aplicabilidade escolar imediata. Trabalho esse que, ainda que centrado na linguagem em uso, deve levar a transdisciplinaridade a sério e saber caminhar por distintas áreas, como Ciências da Computação, Antropologia, Sociologia, dada a complexidade das práticas em foco. Duas grandes contribuições dos estudos do letramento podem e devem ser levadas em conta nesse tipo de perspectiva: em primeiro lugar, a preocupação com o contexto em que tais interações ocorrem. Em segundo lugar, a ideia de que todo letramento é ideológico. Coloca-se em pauta aqui que o aprender, na "escola fora da escola", deve ser encarado de modo semelhante a como ele tem sido abordado na “escola dentro da escola": relacionado a contextos específicos e vinculados a visões de mundo em particular, que tendem a estar em disputa com outros posicionamentos. 


\section{DOSSIÊ ESPECIAL \\ JORDÃO (org.) Letramentos e Multiletramentos no Ensino de Línguas e Literaturas. \\ Revista X, vol.1, 2011}

Uma perspectiva como essa pode ajudar a compreender, por exemplo, como jogadores constroem sentido no ato de jogar e qual a relação que isso tem ou pode ter com as outras esferas de interação e de trocas desse sujeito. Algo relevante, levando em conta os indícios e os dados aqui apresentados sobre videogame, ideologia e identidades. Pode, similarmente, trazer resultados e reflexões relevantes sobre aprendizado e construção de sentido em outros contextos, práticas e formas de interagir - em especial, mas não somente - com novas mídias e tecnologias.

Aliás, dentro da própria sala de aula, há de se começar a pensar em maneiras de tal engajamento se aliar com os recursos disponíveis no cotidiano dos alunos sem reduzir a multiplicidade sinestésica que o meio digital a cada momento oferece ao estudante, como se fossem textos a serem interpretados, decodificados em uma operação de exegese e posteriormente utilizados como material para testes e provas. E por esse motivo, inclusive, é necessário um passo para fora, para se compreender cientificamente usos correntes e contemporâneos da linguagem em meio digital.

Como aponta Lemke (2010, p. 462), há uma necessidade de se compreender, antes de que possamos sequer ensinar, "como vários letramentos e tradições culturais combinam estas modalidades semióticas diferentes para construir significados que são mais do que a soma do que cada parte poderia significar separadamente". Certamente é um trabalho árduo, não só pela volatividade desses usos (o que é característico das forças centrífugas da linguagem), mas pelo fato de que não é raro que as formas com que educandos e educadores lidam com as novas tecnologias divirjam bastante.

Se um professor que busque relações ou aplicabilidades mais diretas desses novos letramentos, mídias e tecnologias pode até se frustrar, ao se olhar para essa espécie de silenciamento, ou de dissolução de possíveis relações mais diretas com a sala de aula com atenção, podemos concluir algo significativo. O debate sobre possíveis relações entre linguagem, cultura e formas de usá-la como transformação social tem como um de seus principais espaços de atuação a educação formal. Isso não quer dizer, porém, que esse é o único palco possível.

Em suma, lado a lado com os estudos já consolidados sobre letramento e educação, esse novo contexto também exige outros recortes e abordagens, em que o uso de linguagens, o compartilhamento e as disputa de saberes, as visões de mundo, os modelos culturais ocorrem incessantemente. Essa contingência dos usos da linguagem nunca deixou de ocorrer. Porém, o prestígio e a importância que reflexões centradas no aprendizado do sujeito têm dado a esses novos espaços colocam tais usos e contextos novamente em evidência. Isso, por sua vez, volta a chamar a atenção para a noção de que os aprendizados são distribuídos e, sendo assim, os diversos locais em que eles ocorrem merecem mais investigações. São necessários, pois, estudos dedicados a se 


\section{DOSSIÊ ESPECIAL \\ JORDÃO (org.) Letramentos e Multiletramentos no Ensino de Línguas e Literaturas. \\ Revista X, vol.1, 2011}

compreender melhor essas novas práticas - dentro da complexidade de seus contextos - e o que elas geram ou podem gerar em uma malha social mais geral. E as contribuições teóricas dos estudos do letramento aqui apresentados podem ter importante papel nisso.

Assim, científica e eticamente, emerge um desafio de se refletir sobre como se manter em linha com as diretrizes ideológicas apresentadas e defendidas na primeira seção em relação a essas novas práticas, sem reduzir ao contexto do ensino formal a busca por investigar tais práticas e partir delas para pensar em formas de atuação que fomentem a reflexão e a criticidade. O prestígio e a ênfase dados atualmente às práticas relacionadas às midias e aos artefatos digitais apenas frisam o quão propício - e mesmo urgente - é, no momento, expandir tudo aquilo de útil que as discussões sobre o letramento já trouxeram para uma reflexão mais ampla sobre cultura, ética, aprendizado e linguagem nas mais diversas práticas letradas da sociedade, sejam mediadas por novas tecnologias ou não.

\section{REFERÊNCIAS}

AUERBACH, E. Considering the Multiliteracies Pedagogy: Looking through the lens of family literacy. In: M. KALANTZIS; COPE, B. (Eds). Transformations in language and learning: perspectives on multiliteracies. Melbourne: Common Ground Publishing, 2001. p. 99-111

BARTON, D. Literacy: An introduction to the ecology of written language. Oxford: Blackwell, 1994.

BOLTER, J. D. Writing Space: Computers, Hypertext, and the Remediation of Print. Mahwah: Lawrence Erlbaum Associates Inc. 2000.

CERVETTI, G.; PARDALES, M.J.; DAMICO, J.S. A tale of differences: Comparing the traditions, perspectives, and educational goals of critical reading and critical literacy.

Reading Online, v. 9, n. 4, Abr. 2001. Disponível em: <http://www.readingonline.org/articles/art_index.asp?HREF=/articles/cervetti/index.html>. Acesso em: 20 jul. 2011.

FRASCA, G. Videogames of Opressed: Videogames as a Means for Critical Thinking and Debate. 118f. Thesis (Master Degree) - Georgia Institute of Technology, Atlanta, 2001.

GEE, J. P. Literacies, schools, and kinds of people in the new capitalism. In: M. KALANTZIS; COPE, B. (Eds). Transformations in language and learning: perspectives on multiliteracies. Melbourne: Common Ground Publishing, 2001. p. 81-98

\section{. What Video Games Have to Teach Us About Learning and Literacy. New}

York: Palgrave/Macmillan, 2003.

GOMES, L. F. Redes sociais e contracultura: a escola fora da escola. In: Simpósio Hipertexto e Tecnologias na Educação, 3, 2010. Recife. Anais... Recife, 2010, p. 1-23. 
HEATH, S. B. Ways With Words. Cambridge: CUP, 1983.

KALANTZIS AND COPE, B. "Multiliteracies": a framework for action. In: M. KALANTZIS; COPE, B. (Eds). Transformations in language and learning: perspectives on multiliteracies. Melbourne: Common Ground Publishing, 2001. p. 53-79

LANGER, J. The Familiar and the Foreign Playing (Post)Colonialism in World of Warcraft. In: CORNELIUSSEN, H. G.; RETTBERG, J. W. (eds). Digital Culture, Play, and Identity: A World of Warcraft ${ }^{\circ}$ Reader. Cambridge: MIT Press, 2008. p. 87-108.

LANKSHEAR, C; KNOBEL, M. New Literacies: Everyday Practices and Classroom Learning. $2^{\mathrm{a}}$ Ed. Maidenhead and New York: Open University Press, 2006.

LEMKE, J. L. Letramento Metamidiático: Transformando Significados e Mídias. Trabalhos em Linguística Aplicada, Campinas, n. 49, v. 2, p. 455-479, Jul./Dez. 2010.

MAGNANI, L. H. Entre a liberdade e a coerção: videogames e construção de sentidos. Ponto Urbe: Revista do Núcleo de Antropologia Urbana da USP, v2.0 Jan, 2008a. Disponível em: <http://n-au.org/pontourbe02/HMagnani.html>. Acesso em: 30 jul. 2011.

. Virando o jogo: uma análise de videogames através de um olhar discursivo

critico. 166f. Dissertação (Mestrado em Linguística Aplicada) Universidade Estadual de Campinas, Campinas, 2008b.

MANOVICH, L. Introduction: New Media from Borges to HTML. In: WARDRIP-FRUIN, N.; MONTFORT, N. The New Media Reader. The MIT Press, 2003

NAHACHEWSKY, J; BEGORAY, D. Authoring the Textual

Classroom in Digital Times. Changing English, n.17, v. 4, p. 421-431, Dec. 2010. Disponível em: <http://www.tandfonline.com/doi/pdf/10.1080/1358684X.2010.528877>

Acesso em: 20 jul. 2011.

RETTBERG, S. Corporate Ideology in World of Warcraft." In: CORNELIUSSEN, H. G.; RETTBERG, J. W. (eds). Digital Culture, Play, and Identity: A World of Warcraft@ Reader. Cambridge: MIT Press, 2008. p. 19-38

ROWSELL, J.; BURKE, A. Reading by Design: Two Case Studies of Digital Reading Practices. Journal of Adolescent \& Adult Literacy, n. 53, v. 2, p. 106-118. 2009.

SCRIBNER, S.; COLE, M. The psychology of literacy. Cambridge: Harvard University Press, 1981.

SOARES, M. Alfabetização e letramento. São Paulo: Editora Contexto, 2003.

STREET, B. At Last: Recent Applications of New Literacy Studies in Educational Contexts. Research in the Teaching of English n. 39, v. 4, p. 417-423. 2005. 